\title{
Prolonged epididymal sperm storage, and the temporal dissociation of testicular and accessory gland activity in the common sheath-tail bat, Taphozous georgianus, of tropical Australia
}

\author{
S. E. Jolly and A. W. Blackshaw \\ Department of Physiology and Pharmacology, University of Queensland, St Lucia, \\ Queensland 4067, Australia
}

\begin{abstract}
Summary. Peak spermatogenic activity of the common sheath-tail bat occurs in autumn, declines over winter and ceases in spring. Accessory glands enlarge in spring when mating occurs, but are regressed at other times of the year. Spermatozoa are stored in the cauda epididymidis throughout the year, and their numbers increase progressively from early summer to late autumn. Sperm storage permits asynchrony of male and female cycles and allows each to be optimally timed in relation to environmental conditions. The temporal separation of primary and secondary sexual functions in the male enables the insemination of females close to ovulation and is a consequence of the burden of sperm storage being placed upon the male.
\end{abstract}

\section{Introduction}

Many reproductive patterns have been described for chiropterans, but attention has largely been focussed on temperate zone bats. Krutzsch (1979) reviewed work on reproductive cycles in nonhibernating bats, including a number of tropical species, but few studies of tropical bats have attempted to quantify male reproductive changes in detail.

Reproduction in members of the Emballonuridae has received particularly scant attention. Kitchener (1973) shed some light on the reproductive cycle of the common sheath-tail bat ( $T$. georgianus), but failed to show any seasonal changes in the male. Kitchener (1976) also investigated Hill's sheath-tail bat ( $T$. hilli), although this was mistaken for the common sheath-tail bat at the time (Kitchener, 1980). Other emballonurid reproductive cycles studied have been those of the Indian sheath-tail bat (T. longimanus) (Gopalakrishna, 1955; Murthy, 1969; Krishna \& Dominic, 1982) and the tomb bat (T. nudiventris) (Al-Robaae, 1967).

The present study details seasonal changes in the male reproductive tract of the common sheath-tail bat, $T$. georgianus, a cave-dwelling insectivore averaging $30 \mathrm{~g}$ in weight. This species ranges throughout tropical Australia and is seasonally monoestrous, giving birth to a single young from October to February (Kitchener, 1973). Male reproductive anatomy of this bat has been described by Kitchener (1973).

\section{Materials and Methods}

\section{Animals}

Between May 1985 and April 1986, 3 adult male bats were collected each month from caves in the Springsure district of central Queensland $\left(24^{\circ} \mathrm{S}\right)$. Shortly after collection these animals were anaesthetized with pentobarbitone sodium and fixed by perfusion with Susa's fixative. Reproductive tracts were removed and fixed in Susa's fixative for a further $24 \mathrm{~h}$, and then stored in $70 \%$ alcohol. All tissues were processed within 3 months of collection. 
Fixed testes and epididymides were dissected free and weighed separately to the nearest $100 \mu \mathrm{g}$. Tissues were dehydrated, cleared, and embedded in paraffin wax. Testes were sectioned at $5 \mu \mathrm{m}$ while the cauda epididymidis and accessory gland complex were serially sectioned at $7 \mu \mathrm{m}$. All sections were routinely stained with Mayer's haematoxylin and eosin (Humason, 1972).

In the field, juveniles were clearly distinguishable from adults for most of the year by the presence of epiphyseal cartilage in the phalangeal joints, dusky pelage and the absence of tooth wear. Young bats approaching 12 months of age (between November and January) were distinguishable on histological features, notably a lack of spermatozoa in the cauda epididymidis and small seminiferous tubules with only Sertoli cells and spermatogonia.

\section{Quantitative histology}

Analysis. Analyses were performed on the testes, cauda epididymidis and accessory gland complex of each animal. Estimates of histological values were made by stereological analysis of the image produced by a video camera mounted on a Zeiss Photomicroscope 2. This method avoided the inherent selection bias of direct measurement and permitted the use of large sample sizes.

Volumetric proportions were estimated by calculating the frequency with which tissue components fell under a lattice of points (Weibel et al., 1966) superimposed on the video screen. The equation used was $\mathrm{Vv}=\mathrm{h} /(\mathrm{h}+\mathrm{m}$ ) (Chalkley, 1943) where $\mathrm{Vv}=$ the volume density of the structure being measured, $\mathrm{h}=$ the number of points hitting the structure and $\mathrm{m}=$ the number of points missing the structure. Calculated proportions were used in conjunction with organ weights and volumes to make comparative estimates of component weights and volumes.

It was not possible to separate and weigh the component glands of the accessory gland complex, and so a volume estimate was made from stained and mounted sections. This was obtained by measuring the cross-sectional area of each gland every $140 \mu \mathrm{m}$ (every 20 sections) and the fixed volume was taken to be the sum of the cross-sectional areas multiplied by $140 \mu \mathrm{m}$.

The dissection of the epididymis from the testis frequently damaged the capsule with a resultant increase in intertubular space. This artefact was corrected for in volumetric determinations by subtracting the volume of the intertubular space from the total volume under consideration.

The average diameter of Leydig cell nuclei was estimated by superimposing on their image a grid of lines of a known distance apart. The diameter of the nuclei (D) was proportional to the frequency their perimeters intersected the lines, and was calculated from the question $(D=I d / 2$ where $I=$ the mean number of grid line intersections per nucleus and $d=$ the relative distance between the lines $(d \geq D)$. This was derived from the equation of Loud (1962), $\mathrm{P}=\mathbf{I} \pi / 2$ where $\mathbf{P}=$ the perimeter.

Tubules and gland acini were assumed to be cylinders and average diameters were estimated by superimposing on their image a lattice of points and a grid of lines (Weibel et al., 1966). The diameter of a cylinder is four times the ratio of the volume density to the surface density. Surface density (Sv) was calculated from the equation $\mathrm{Sv}=2 \mathrm{I} / \mathrm{L}$ (Weibel, 1980 ) and from this the equation for the average diameter (D) of cylindrical structures was derived as $D=2 \mathrm{VvL} / \mathrm{I}$ where $\mathbf{I}=$ the number of intersections the superimposed lines makes with the structure being measured, $\mathrm{L}=$ the total relative length of the superimposed lines, and $\mathrm{Vv}=$ the volume density.

Epithelial thickness was calculated in a similar manner by assuming the epithelium to be analogous to the wall of a cylinder. The average thickness is half the difference between the internal and external diameters. The equation for the calculation of thickness $(\mathrm{T})$ is therefore:

$$
\mathrm{T}=[2(\mathrm{Vvl}+\mathrm{Vvw}) \mathrm{L} / \mathrm{Ie}-2 \mathrm{VvlL} / \mathrm{II}] / 2
$$

or by rearrangement $\mathrm{T}=\mathrm{VvwL} /(\mathrm{Ii}+\mathrm{Ie})$ where $\mathrm{Vvl}=$ the volume density of the cylinder lumen, $\mathrm{Vvw}=$ the volume density of the cylinder wall, $\mathrm{Ii}=$ the number of intersections between the superimposed lines and the internal boundary of the cylinder wall and $\mathrm{Ie}=$ the number of intersections between the superimposed lines and the external boundary of the cylinder wall.

Counts were made of cell nuclei within known volumes of testes. A direct count tended to overestimate the number present because with a nuclear diameter similar to section thickness, many structures counted as nuclei were only split fractions. This error was proportional to the perimeter size of the nuclei and the section thickness (Aherne, 1967). A line grid was superimposed on images of the seminiferous epithelium, and counts were made of the apparent number of nuclei within the grid and the number of intersections between the grid lines and nuclear perimeters. The formula used to find the true number of nuclei per volume was $N=2 n V / A(I d+2 t)$ (Aherne, 1967) where $N=$ the true number of nuclei contained in the volume $\mathrm{V}, \mathrm{n}=$ the number of nuclear transections within the area of the grid, $\mathrm{A}=$ the surface area of the grid, $I=$ the mean number of grid line intersections per nucleus, $d=$ the relative distance between the lines and $\mathrm{t}=$ the section thickness.

From counts of nuclei comparative estimates of the number of each cell class per bat were obtained, by multiplying the number of cells per $\mu \mathrm{l}$ of testis (corrected for space artefact) by the total weight of the animal's testes in $\mathrm{mg}$. Shrinkage due to histological processing was assumed to be uniform and the specific gravity of the testes was taken as 1 .

Statistical differences between means were tested using Student's $t$ test.

Samples. For each bat, analyses were performed on one randomly chosen area from each of 30 separate histological sections of the cauda epididymidis, seminal vesicle/ampulla, and prostate. The 30 sections were taken at evenly spaced intervals along the length of each organ. 
Table 1. Autumn and spring means ( \pm s.e.m. for 9 bats/season), and values of $t$, of histological measurements of the testis, seminal vesicle/ampulla and prostate of common sheath-tail bats

\begin{tabular}{|c|c|c|c|c|c|c|}
\hline \multirow{2}{*}{ Testes } & \multirow[b]{3}{*}{ (mg) } & \multicolumn{2}{|c|}{ Autumn } & \multicolumn{2}{|c|}{ Spring } & \multirow[t]{2}{*}{$t$} \\
\hline & & & & & & \\
\hline Total testis weight & & 38 & $\pm 4 \cdot 7$ & 20 & \pm 1.4 & $3 \cdot 5^{* *}$ \\
\hline Epithelial weight & (mg) & 32 & \pm 3.9 & 14 & \pm 0.8 & $4 \cdot 4^{* *}$ \\
\hline Epithelial thickness & $(\mu \mathrm{m})$ & 59 & $\pm 2 \cdot 8$ & 34 & \pm 2.8 & $6 \cdot 3 * *$ \\
\hline Lumen diameter & $(\mu \mathrm{m})$ & 59 & $\pm 2 \cdot 1$ & 61 & \pm 3.7 & 0.6 \\
\hline Tubular diameter & $(\mu \mathrm{m})$ & 187 & $\pm 7 \cdot 5$ & 148 & \pm 2.8 & $4 \cdot 7^{* *}$ \\
\hline Interstitial tissue & (mg) & 0.8 & \pm 0.09 & $0.9=$ & \pm 0.09 & $0 \cdot 9$ \\
\hline Leydig nuclear diam. & $(\mu \mathrm{m})$ & $6 \cdot 0$ & \pm 0.18 & $6 \cdot 0=$ & \pm 0.15 & $0 \cdot 0$ \\
\hline Spermatogonia & $\left(\times 10^{-6} / \mathrm{bat}\right)$ & 1.48 & \pm 0.15 & $1.09=$ & \pm 0.27 & $1 \cdot 3$ \\
\hline Spermatocytes & $\left(\times 10^{-6} /\right.$ bat $)$ & 3.77 & \pm 0.45 & $0.07=$ & \pm 0.04 & $8 \cdot 1^{* *}$ \\
\hline Round spermatids & $\left(\times 10^{-6} /\right.$ bat $)$ & 4.84 & \pm 0.96 & $0.02=$ & \pm 0.02 & $5 \cdot 0^{* *}$ \\
\hline Spermatozoa & $\left(\times 10^{-6} / \mathrm{bat}\right)$ & 4.63 & \pm 0.84 & $0.03=$ & \pm 0.03 & $5 \cdot 5^{* *}$ \\
\hline Sertoli cells & $\left(\times 10^{-6} /\right.$ bat $)$ & 0.94 & \pm 0.13 & $1 \cdot 57=$ & \pm 0.20 & $2 \cdot 6^{*}$ \\
\hline Leydig cells & $\left(\times 10^{-6} / \mathrm{bat}\right)$ & 0.59 & \pm 0.13 & $0.59=$ & \pm 0.07 & $0 \cdot 0$ \\
\hline \multicolumn{7}{|l|}{ Ampulla/seminal vesicle } \\
\hline Volume of gland & $(\mu 1)$ & $4 \cdot 8$ & \pm 1.28 & $14 \cdot 8 \pm$ & \pm 2.39 & $3 \cdot 7^{* *}$ \\
\hline Volume of secretion & $(\mu l)$ & $1 \cdot 7$ & \pm 0.77 & $10 \cdot 0 \pm$ & \pm 2.34 & $3 \cdot 4^{* *}$ \\
\hline Acinar diameter & $(\mu \mathrm{m})$ & 97 & \pm 7.03 & 163 & $\pm 12 \cdot 7$ & $4 \cdot 6^{* *}$ \\
\hline Epithelial thickness & $(\mu \mathrm{m})$ & $12 \cdot 3$ & \pm 1.53 & $9.9=$ & \pm 0.99 & $1 \cdot 3$ \\
\hline \multicolumn{7}{|l|}{ Prostate } \\
\hline Volume of gland & $(\mu \mathrm{l})$ & 1.9 & \pm 0.20 & $3 \cdot 5$ & \pm 0.40 & $3 \cdot 6^{* *}$ \\
\hline Acinar diameter & $(\mu \mathrm{m})$ & 77 & \pm 6.68 & 98 & $\pm 4 \cdot 20$ & $2 \cdot 7^{*}$ \\
\hline
\end{tabular}

${ }^{*} P<0.05 ;{ }^{* *} P<0.01$.

Testicular analysis was performed on both testes of all bats, 15 areas being chosen at random from a single histological section of each testis. To determine the average diameter of Leydig cell nuclei, 15 areas of interstitial tissue were selected from a section of each testis. Only areas with abundant Leydig cell nuclei were chosen.

\section{Results}

\section{Testes}

Peak spermatogenesis occurred in autumn when testes and seminiferous epithelium were significantly heavier than in spring. From late summer to early winter there was an increase in the thickness of the seminiferous epithelium and the tubule diameter, and an increased abundance within the testes of spermatocytes, spermatids and spermatozoa. Spermatogenesis declined over winter and ceased in spring. There was no seasonal change in the weight of interstitial tissue, Leydig cell abundance, or Leydig cell nuclear diameter. Sertoli cells were recorded in greater numbers in spring, but this was an apparent increase only, due to their greater visibility in the absence of the majority of the germ cells (Table 1; Fig. 1).

\section{Prostate and ampulla/seminal vesicle}

There was a sharp increase in the volume and acinar diameter of the prostate and ampulla/ seminal vesicle in spring. The volume of secretion within the ampulla/seminal vesicle also increased significantly at this time. There was no significant change in the thickness of the epithelium (Table 1; Fig. 1). 

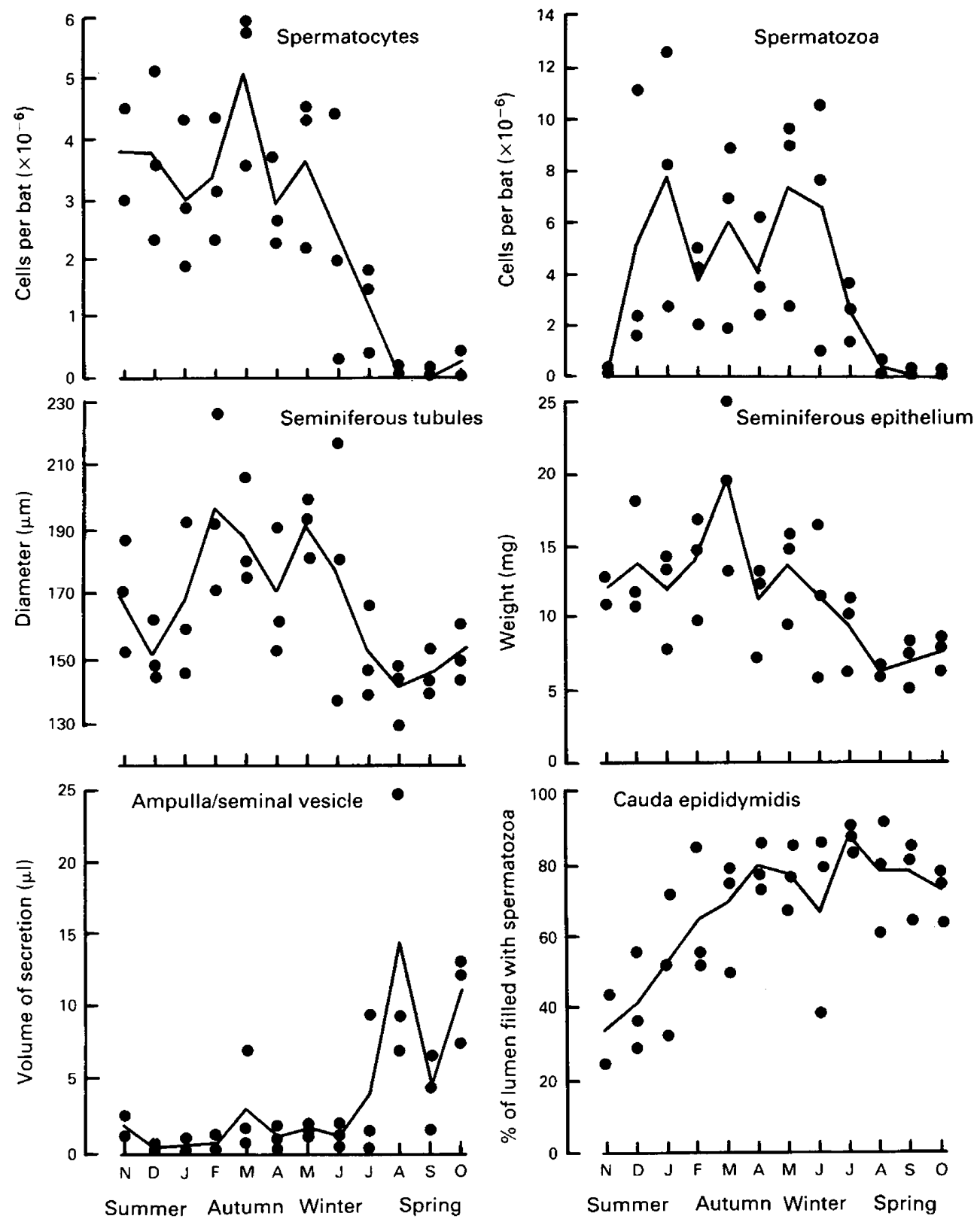

Fig. 1. Seasonal changes in the abundance of spermatocytes and spermatozoa within the testes, the diameter of the seminiferous tubules, the weight of the seminiferous epithelium, the volume of secretion within the ampulla/seminal vesicle and the proportion of the cauda epididymidal lumen filled with spermatozoa in common sheath-tail bats.

\section{Cauda epididymidis}

Spermatozoa were present in the cauda epididymidis throughout the year. The proportion of the lumen filled with spermatozoa declined sharply at the end of spring and then increased with spermatogenic activity (Fig. 1). 


\section{Discussion}

It is evident from this study that spermatozoa are stored in the cauda epididymidis of the common sheath-tail bat for many months, while in females of this species sperm storage does not occur (Kitchener, 1973).

Kitchener (1973) also reported a gestation period of approximately 4 months, with births occurring from October to February, and copulation most probably from July to November. A study of female common sheath-tail bats in central Queensland showed that births are confined almost exclusively to the month of December, with vaginal smears indicating that females are in oestrus in the months of August, September and October (S. E. Jolly, unpublished).

The upsurge in the volume of accessory gland secretion recorded in the present study strongly supports the period August to October as the season in which copulation takes place, a time when spermatogenesis had ceased in all individuals investigated. With peak spermatogenesis from February to March, fertilization must be with spermatozoa stored for a minimum of 3 months.

Sperm storage is a common feature of male and female temperate-zone bats (see Racey, 1979) and in recent years has been recorded in females of the tropical species Pipistrellus ceylonicus (Gopalakrishna \& Madhavan, 1971), Tylonycteris pachypus and T. robustula (Medway, 1972), Lasiurus ega, Eptesicus furinalis and Myotis albescens (Myers, 1977), Scotophilus heathi (Krishna \& Dominic, 1978; Gopalakrishna \& Madhavan, 1978) and P. mimus (Krishna, 1985).

Storage of spermatozoa in male bats from the tropics would appear less common, but has been reported to occur to a limited extent in the Paraguayan bat, Lasiurus ega (Myers, 1977), and the Indian bats Hipposideros speoris (Gopalakrishna \& Bhatia, 1980) and Rhinopomona hardwickei (Karim \& Banerjee, 1985). In these species most females are inseminated at a time when spermatogenesis is taking place in the male, and the stored spermatozoa are probably a reserve to inseminate females which fail to conceive in the main breeding season. Extended cauda epididymal sperm storage such as that apparent in this study has not previously been described for any tropical bat.

A capacity to store spermatozoa confers upon a species the freedom to phase shift male and female reproductive cycles, and so time each cycle optimally in relation to environmental conditions. Conversely, compelling reasons for male and female cycles to be out of step must have existed for the mechanism to have evolved in the first place.

In the vast majority of seasonally breeding bats, female cycles are timed so that pregnancy, lactation and growth of the young coincide with seasonal peaks in nutrition. In females from the temperate zones, and especially in the hibernators, reproductive activity occurs in spring and summer (Oxberry, 1979), while in females from the tropics this activity usually coincides with periods of increased rainfall (Racey, 1982).

The timing of the male cycle would appear to depend more on temperature than nutrition and even in tropical sperm-storing bats spermatogenesis is generally interrupted or suppressed during the coldest months of the year (Gopalakrishna \& Madhavan, 1971; Myers, 1977; Krishna \& Dominic, 1981; Krishna, 1985). The only recorded exceptions are the flat headed bats Tylonycteris pachypus and T. robustula from Malaysia (Medway, 1972). Working on specimens from just $3^{\circ}$ north of the equator, Medway found a distinct spermatogenic cycle in these bats, but spermatogenesis proceeded without interruption through the coolest months of the year and did not coincide with peaks in rainfall or nutrition. The mechanisms controlling the male reproductive cycle in these bats need further investigation.

In central Queensland the rainy season extends from November to March, coinciding with pregnancy, lactation and growth of the young of the common sheath-tail bat. Spermatogenesis begins in summer and declines with the onset of cooler weather at the end of autumn.

Gustafson (1979) suggested that the best indication of accessory gland activity may be the thickness of accessory gland epithelium. In the present study there were no significant changes in the thickness of the accessory gland epithelium, and the slight thinning observed in spring appeared to be due to distension of the glands by secretion. It seems likely that peak activity of the accessory 
glands in the common sheath-tail bat occurs immediately before the sudden increase in secretion volume in spring, 6 months after the spermatogenic peak.

The asynchrony of primary and secondary sexual functions is a common feature of the hibernating bats (Miller, 1939; Pearson et al., 1952; Krutzsch, 1961, 1975; Racey, 1974; Racey \& Tam, 1974; Gustafson, 1976, 1979; Bernard, 1986; Krutzsch \& Crichton, 1986) but has not previously been reported for a tropical bat, while even in temperate-zone bats in which asynchrony does occur the separation is never as dichotomous as it would appear to be in the common sheath-tail bat. Clearly in this species the separation enables the insemination of females close to ovulation, but an interesting question is why the burden of sperm storage falls on the male with the consequential complications of the separation of primary and secondary sexual functions.

In the present study we were unable to demonstrate any seasonal changes in Leydig cells or interstitial tissue and the factors controlling the unusual timing of the accessory gland activity in this bat are being further investigated.

\section{References}

Aherne, W. (1967) Methods of counting discrete tissue components in microscopical sections. J. roy. Microsc. Soc. 87, 493-508.

Al-Robaae, K. (1967) Notes on the biology of the tomb bat, Taphozous nudiventris magnus v. Wettstein 1913, in Iraq. Saugetierk. Mitt. 16, 21-26.

Bernard, R.T.F. (1986) Seasonal changes in plasma testosterone concentrations and Leydig cell and accessory gland activity in the Cape horseshoe bat (Rhinolophus capensis). J. Reprod. Fert. 78, 413-422.

Chalkley, H.W. (1943) Methods for quantitative morphological analysis of tissue. J. natn. Cancer Inst. 4, $47-62$.

Gopalakrishna, A. (1955) Observations on the breeding habits and ovarian cycle in the Indian sheath-tailed bat, Taphozous longimanus (Hardwicke). Proc. natn. Inst. Sci. India B 21, $29-41$.

Gopalakrishna, A. \& Bhatia, D. (1980) Storage of spermatozoa in the epididymis of the bat, Hipposideros speoris (Schneider). Curr. Sci. 49, 951-953.

Gopalakrishna, A. \& Madhavan, A. (1971) Survival of spermatozoa in the female genital tract of the Indian vespertilionid bat Pipistrellus ceylonicus chrysothrix (Wroughton). Proc. Indian Acad. Sci. B 73, 43-49.

Gopalakrishna, A. \& Madhavan, A. (1978) Viability of inseminated spermatozoa in the Indian vespertilionid bat Scotophilus heathi (Horsefield). Indian J. exp. Biol. 16, 852-854.

Gustafson, A.W. (1976) A study of the annual male reproductive cycle in a hibernating vespertilionid bat Myotis lucifugus lucifugus with emphasis on the structure and function of the interstitial cells of Leydig. Diss. Abstr. B 36, 4792-4793.

Gustafson, A.W. (1979) Male reproductive patterns in hibernating bats. J. Reprod. Fert. 56, 317-333.

Humason, G.L. (1972) Animal Tissue Techniques. W.H. Freeman \& Co., San Francisco.

Karim, K.B. \& Banerjee, S. (1985) Storage of spermatozoa in the epididymis of the tropical bat Rhinopomona hardwickei hardwickei (Gray). Anat. Rec. 211, 95A, Abstr.

Kitchener, D.J. (1973) Reproduction in the common sheath-tailed bat, Taphozous georgianus (Microchir- optera: Embalionuridae), in Western Australia. Aust. J. Zool. 21, 375-389.

Kitchener, D.J. (1976) Further observations on reproduction in the common sheath-tailed bat, Taphozous georgianus Thomas, 1915 in Western Australia, with notes on the gular pouch. Rec. West. Aust. Mus. 4, $335-347$.

Kitchener, D.J. (1980) Taphozous hilli sp. nov. (Chiroptera: Emballonuridae), a new sheath-tailed bat from Western Australia and Northern Territory. Rec. West. Aust. Mus. 8, 161-169.

Krishna, A. (1985) Reproduction in the Indian pipistrelle bat Pipistrellus mimus. J. Zool., Lond. 206, 41-51.

Krishna, A. \& Dominic, C.J. (1978) Storage of spermatozoa in the female genital tract of the vespertilionid bat, Scotophilus heathi. J. Reprod. Fert. 54, 319-321.

Krishna, A. \& Dominic, C.J. (1981) Reproduction in the vespertilionid bat Scotophilus heathi Horsefield. Archs Biol. 92, 247-258.

Krishna, A. \& Dominic, C.J. (1982) Reproduction in the Indian sheath-tailed bat. Acta theriol. 27, 97-106.

Krutzsch, P.H. (1961) The reproductive cycle in the male vespertilionid bat Myotis velifer. Anat. Rec. 139, 309, Abstr.

Krutzsch, P.H. (1975) Reproduction of the canyon bat Pipistrellus hesperus, in Southwestern United States. Am. J. Anat. 143, 163-200.

Krutzsch, P.H. (1979) Male reproductive patterns in non-hibernating bats. J. Reprod. Fert. 56, 333-344.

Krutzsch, P.H. \& Crichton, E.G. (1986) Reproduction of the male eastern pipistrelle, Pipistrellus subflavus, in the north-eastern United States. J. Reprod. Fert. 76, 91-104.

Loud, A.V. (1962) A method for the quantitative estimation of cytoplasmic structures. J. Cell Biol. 16, $481-487$.

Medway, Lord (1972) Reproductive cycles of the flat headed bats $T y$ lonycteris pachypus and $T$. robustula (Chiroptera:vespertilionidae) in a humid equatorial environment. Zool. J. Linn. Soc. 51, 33-61.

Miller, R.E. (1939) The reproductive cycle in the male bats of the species Myotis lucifugus lucifugus and Myotis grisescens. J. Morph. 64, 267-295. 
Murthy, K.V.R. (1969) Histophysiology of the penis in the Indian sheath-tailed bat Taphozous longimanus (Hardwicke) with notes on the morphology of the internal genitalia. J. Zool. Soc. India 21, 149-159.

Myers, P. (1977) Patterns of reproduction of four species of vespertilionid bats in Paraguay. Univ. Calif. Publs Zool. 107, 1-44.

Oxberry, B.A. (1979) Female reproductive patterns in hibernating bats. J. Reprod. Fert. 56, 359-367.

Pearson, O.P., Koford, M.R. \& Pearson, A.K. (1952) Reproduction of the lump nosed bat (Corynorhinus rafinesquei) in California. J. Mammal. 33, 273-320.

Racey, P.A. (1974) The reproductive cycle in male noctule bats Nyctalus noctula. J. Reprod. Fert. 41, 169 182 .
Racey, P.A. (1979) The prolonged storage and survival of spermatozoa in Chiroptera. J. Reprod. Fert. 56, 391-402.

Racey, P.A. (1982) Ecology of bat reproduction. In Ecology of Bats, pp. 57-104. Ed. T. H. Kunz. Plenum Press, New York.

Racey, P.A. \& Tam, W.H. (1974) Reproduction in male Pipistrellus pipistrellus (Mammalia: Chiroptera). $J$. Zool., Lond. 172, 101-122.

Weibel, R.W. (1980) Stereological Methods, Vol. 2. Academic Press, London.

Weibel, R.W., Kistler, G.S. \& Scherle, W.F. (1966) Practical stereological methods for morphometric cytology. J. Cell Biol. 30, 23-38.

Received 3 February 1987 